\title{
QUIMIOTERAPIA E.V. E I.A. - ASSISTENCIA DE ENFERMAGEM
}

Vilma Thereza Alquieri *

$\operatorname{ReBEn} / 04$

ALQUIERI, V.T. - Quimioterapia E.V e I.A - Assistência de Enfermagem. Rev. Bras.

Enf.; DF, 33 : 424-427, 1980.

\section{INTRODUÇĀO}

O Hospital Erasto Gaertner pertence à Liga Paranaense de Combate ao Cancer, fundada a 8 de março de 1947 por uma equipe de médicos sob a prosidência do Professor Doutor Erasto Gaertner; destina-se a pacientes portadores de tumores malignos, procedentes das mais diversas camadas sociais. No momento, esse hospital atende, em média, 140 (cento e quarenta) pacientes, diariamente.

Atualmente, o Hospital Erasto Gaertner utiliza como tratamento coadjuvante, nos casos de cancer, a aplicação de quimioterapia E.V. e I.A. A aplicação de quimioterápicos é feita a nível de internação e a nível ambulatorial, numa média de 30 (trinta) a 40 (quarenta) aplicações diárias.

Responsáveis que somos pelo Serviço de Enfermagem, sentimos premente necessidade de dar assistência contínua e intensa a essas aplicações, bem como ao preparo e à utilização das drogas nelas utilizadas.

A literatura pertinente ao assunto é pobre, pois, ao revê-la, somente encontramos o trabalho de MILLER 1, que versa sobre a atuação da enfermeira oncológica na aplicação de quimioterápicos. Encontramos abordagem ao assunto, também, em livros de Farmacologia, quais sejam o de RAMOS 2 e o de SANS-SABRAFEN 3.

\section{CONSIDERAÇÕES GERAIS SOBRE' A QUIMIOTERAPIA}

A Quimioterapia é uma arma do arsenal terapêutico usada em cancerologia e que se baseia no uso de medicamentos citostáticos e antiblásticos, com a finalidade de matar a célula cancerosa, agindo a nível celular. Ela objetiva destruir possíveis micrometástases ocultas ao exame físico, de laboratório, $\mathrm{RX}$ e mapeamento.

\footnotetext{
* Enfermeira-Chefe do Hospital Erasto Gaertner - Docente de enfermagem cirúrgica da Escola Técnica de Enfermagem "Catarina Labouré" - Curitiba-PR.
} 
ALQUIERI, V.T. - Quimioterapia E.V e I.A - Assistência de Enfermagem. Rev. Bras.

Enf.; DF, 33 : 424-427, 1980.

A via mais usada é a endovenosa, seguindo-se-lhe a intra-arterial. Também são utilizadas a via intracavitária, oral, retal e as aplicações locais.

Como efeitos colaterais da aplicação de quimioterápicos podem aparecer: náuseas, vômitos, flebite química, estomatite (aftas), alopécia, leucopenia, cardiotoxidade, dermatose, febre, diarréias, irritabilidade, euforia, dermatite e outras manifestações, de acordo com o medicamento empregado.

\section{ASSISTÊNCIA PSICOLÓGICA}

A assistência psicológica ao paciente é assaz importante, mormente em se tratando dos cancerosos. Essa assistência processa-se por meio de orientação em grupo ou individual. Quando trabalhamos, tanto em grupo como individualmente, buscamos atender ao máximo às necessidades básicas dos pacientes.

Por outro lado, no momento em que a maioria dos pacientes está sentada, uns recebendo soro, outros a medicação determinada, ou deixamos a televisão ligada ou damos orientação geral, de caráter prático, na sala de quimioterapia, sobre os sintomas sentidos pelos pacientes e que mais os atemorizam, como, por exemplo: náuseas, vômitos, febre, irritabilidade, euforia, anorexia. Esses sintomas, via de regra, desaparecem depois de algumas horas ou de alguns dias. Quando persistirem, os pacientes devem voltar ao hospital para exame médico.

Nosso trabalho junto a esses pacientes é, por vezes, árduo e os efeitos desejados raramente são constatados; todavia, procuramos sempre incentiválos para que vejam ou enfrentem o problema com otimismo. Muitas vezes, durante a aplicação da droga, conversamos bastante com os pacientes, buscando deixá-los à vontade, descontraindo-os. Inclusive, fazemo-lhes várias perguntas relacionadas à sua família, meio ambiente, amizades, parentes, etc.

Quando os pacientes são extrovertidos, deixamo-los falar livremente, com toda a espontaneidade de que são capazes.

Temos constatado, então, que a aceitação do tratamento melhorou, e muito, depois que passamos a realizar esse tipo de assistência concomitantemente às aplicações de quimioterápicos, a nivel ambulatorial.

\section{CONSERVAÇÃO E PREPARAÇÃO DE MEDICAMENTOS}

O conservar e preparar medicamentos requer que deles tenhamos um bom conhecimento, em face de certas características que apresentam. Medicamentos como Bioact D, DTIC e Oncovim necessitam permanecer guardados na geladeira até o momento de o soro estar devidamente instalado na veia do paciente. Outros, como Oncocloramin e Oncothiotepa, não devem ser expostos à luz antes de seu preparo, o que deve ser feito junto à cabeceira do paciente; outrossim, só podem ser retirados do frasco no momento de serem injetados, e isso rapidamente. caso, por exemplo, do DTIC, cuja retirada do frasco e respectiva aplicação não podem ultrapassar o periodo de tempo de 1 (um) minuto. O Bioact $D$, para citar outro exemplo, é preparado após a instalação do soro, e o tempo decorrido desde a sua retirada do frasco e aplicação não pode ultrapassar de 10 (dez) minutos.

\section{QUIMIOTERAPIA ENDOVENOSA}

A via endovenosa é a mais usada no tratamento quimioterápico devido à rapidez de absorção do produto injetado, embora necessite de pessoal devidamente treinado para aplicação, em face de conseqüências danosas que po- 
ALQUIERI, V.T. - Quimioterapia E.V e I.A - Assistência de Enfermagem. Rev. Bras. Enf.; DF, 33 : 424-427, 1980.

dem ocorrer, como queimaduras, edemas, etc.

\subsection{Técnica}

a) Instalar o soro glicosado $5 \%$ $250 \mathrm{ml}$; deixar correr $50 \mathrm{ml}$ para ter certeza de que o mesmo se encontra dentro da veia.

b) Injetar as drogas sintomáticas (Plasil, Commel).

c) Verificar o modo de preparo e conservação rotineira dos medicamentos para cada droga utilizada nos tratamentos.

d) Injetar quimioterápicos na diluição recomendada, separadamente.

e) Abrir o soro rapidamente, após a aplicação de quimioterápicos, para lavar as veias.

f) Tomar extremo cuidado para não injetar quimioterápicos fora da veia.

g) Evitar a administração de medicamentos nos membros inferiores.

h) Cuidar sempre, para a injeção correta da dose estabelecida.

\subsection{Cuidados especiais}

a) Lavar a veia para evitar queimadura, fibrose e necrose, pois o medicamento é altamente cáustico, causando ação no endotélio venoso.

b) Não fazer quimioterapia nos membros que sofreram esvaziamento ganglionar. Exemplo: mastectomia. Há uma diminuição da circulação linfática de retorno, provocando o linfo-edema e favorecendo a instalação de infecção de difícil controle.

c) Evitar os membros inferiores para administração do medicamento, devido à dificuldade do retorno venoso. Lembrar, também, que o paciente canceroso tem predisposição para tromboflebite, em face da doença de que é portador, pois os fatores da coagulação estão todos aumentados, provocando um estado de hipercoagulabilidade.

d) Para os medicamentos que causam alopécia (Adriablastina, Alkeran, Aracetin, Daunoblastina, $\mathbf{E} \boldsymbol{n} \mathbf{d} \mathrm{x}$ a $\boldsymbol{n}$, Fluoro-Uracil, Myleran, Oncovin, Velban) fazemos o garroteamento do couro cabeludo, diminuindo, assim, a parte sangüinea a esse nível e, portanto, a diminuição do fluxo de medicamento, evitando a queda dos cabelos, provocada pelos quimioterápicos acima citados. Em alguns casos é também usada a bolsa de gelo com a mesma finalidade.

e) No caso de extravasar medicamento no local de aplicação, principalmente na pele sensível à formação de necrose, usamos bolsa de gelo, diminuindo a difusão do medicamento a nível tecidual, obstaculizando, assim, o aumento da necrose.

\section{QUIMIOTERAPIA INTRA-ARTE- RIAL}

E a técnica pela qual usamos a artéria como veículo para introdução dos medicamentos. Na maioria das vezes, essa artéria é que possibilita maior irrigação na massa tumoral. Obtemos, assim, grau de dosagem a esse nível e diminuição a nível sistêmico, conseguindo um maior efeito sobre a célula cancerosa e diminuindo, consideravelmente, os efeitos colaterais sistêmicos na célula normal.

\subsection{Técnica}

a) Preparar o soro fisiológico na quantidade prescrita e adicionar os medicamentos juntamente com $2 \mathrm{ml}$ de heparina para cada $1.000 \mathrm{ml}$ de soro.

b) Observar, para que não haja entrada de ar no frasco que contém os quimioterápicos.

c) O gotejamento deve ser regulado no cronoinfusor, de maneira a se 
ALQUIERI, V.T. - Quimioterapia E.V e I.A - Assistência de Enfermagem. Rev. Bras. Enf.; DF, 33 : 424-427, 1980.

manter, durante 24 horas, em média, 12 gotas por minuto.

d) Após o término do ciclo de quimioterapia, o cateter deve ser mantido fechado com heparina no seu interior.

e) As aplicações diretas de quimioterapia na artéria deverão ser feitas com a máxima assepsia. Por sua vez, o cateter deve ser mantido fechado depois de aplicação com heparina.

\subsection{Cuidados especiais}

Fechar o soro e chamar o médico com a máxima urgência, sempre que o paciente se queixar de formigamento ou paralisia de qualquer parte do corpo, pois os medicamentos têm ação cáustica na parede da artéria. A artéria entra em espasmo, diminuindo o fluxo de sangue, ocorrendo, conseqüentemente, a hipoxia tecidual.

A hipoxia aumenta a permeabilidade dos capitalares, e esse aumento, por sua vez, produz um edema, o que faz com que haja compressão nas áreas motoras, ocasionando, então, o formigamento ou a paralisia.

\section{CONCLUSÃO}

Os pacientes cancerosos são pessoas geralmente carentes não só de recursos materiais, mas, especialmente, de recursos afetivos.

No nosso hospital procuramos atender o indivíduo como um todo; damos muita atenção ao aspecto psicológico e, na medida do possível, buscamos atender às suas preferências alimentares, favorecer visitas, além de realizarmos uma série de outrús cuidados individualizados.

A equipe de Enfermagem recebe orientação contínua e está preparada para toda e qualquer solicitação dos pacientes, a fim de proporcionar-lhes assistência de enfermagem adequada $e$ eficaz.

E assim procedendo, notamos que, embora o prognóstico seja, na maioria das vezes, dos mais sérios, os pacientes sentem-se bem em nosso meio, mantendo excelente relacionamento com a equipe de Saúde e de Enfermagem.

Ao retornarem ao hospital, demonstram alegria, cumprimentam os funcionários, fazem questão de expressar sua gratidão a cada um deles, em particular.

Recebemos cartas de pacientes e familiares, agradecendo-nos o ambiente familiar que lhes proporcionamos.

\section{RECOMENDAÇÓES}

a) Que as enfermeiras que trabalham em Oncologia façam pesquisas e publiquem mais artigos sobre 0 assunto.

b) Que todo o pessoal de enfermagem que aplica a quimioterapia, receba treinamento e orientação especifica sobre o medicamento, sua conservação, aplicação e cuidados.

\section{BIBLIOGRAFIA}

1. MILLER, S.A. - Oncology nurse chemotherapy. American Journal of Nursing. June, 1977.

2. RAMOS, J. R. - Oncologia clinica. São Paulo, Sarveei, 1974.
3. SANS-SABRAFEN, J. C. \& COSTA, A. R. R. - Manual de quimioterapia anti-neoplosica. Barcelona, Ediciones Toray, 1976. 